\title{
Platelet-activating Factor Acetylhydrolase Deficiency \\ A Missense Mutation Near the Active Site of an Anti-inflammatory Phospholipase
}

\author{
Diana M. Stafforini, ${ }^{\star}$ Kei Satoh, ${ }^{\ddagger}$ Donald L. Atkinson, ${ }^{\star}$ Larry W. Tjoelker, ${ }^{\S}$ Chris Eberhardt, ${ }^{\S}$ Hidemi Yoshida, ${ }^{\ddagger}$ \\ Tada-atsu Imaizumi, ${ }^{\ddagger}$ Shigeru Takamatsu, ${ }^{\ddagger}$ Guy A. Zimmerman, ${ }^{\|}$Thomas M. Mclntyre, ${ }^{\|}$Patrick W. Gray, ${ }^{\S}$ \\ and Stephen M. Prescott* \\ *The Program in Human Molecular Biology and Genetics, Eccles Institute of Human Genetics, and ${ }^{\text {Cardiovascular Research and }}$ \\ Training Institute, University of Utah, Salt Lake City, Utah 84112; ${ }^{\ddagger}$ Department of Pathological Physiology, Institute of Neurological \\ Diseases, Hirosaki University School of Medicine, Hirosaki 036, Japan; and ${ }^{\S}$ ICOS Corporation, Bothell, Washington 98021
}

\begin{abstract}
Deficiency of plasma platelet-activating factor (PAF) acetylhydrolase is an autosomal recessive syndrome that has been associated with severe asthma in Japanese children. Acquired deficiency has been described in several human diseases usually associated with severe inflammation. PAF acetylhydrolase catalyzes the degradation of PAF and related phospholipids, which have proinflammatory, allergic, and prothrombotic properties. Thus, a deficiency in the degradation of these lipids should increase the susceptibility to inflammatory and allergic disorders. Miwa et al. reported that PAF acetylhydrolase activity is absent in $4 \%$ of the Japanese population, which suggests that it could be a common factor in such disorders, but the molecular basis of the defect is unknown. We show that inherited deficiency of PAF acetylhydrolase is the result of a point mutation in exon 9 and that this mutation completely abolishes enzymatic activity. This mutation is the cause of the lack of enzymatic activity as expression in $E$. coli of a construct harboring the mutation results in an inactive protein. This mutation as a heterozygous trait is present in $27 \%$ in the Japanese population. This finding will allow rapid identification of subjects predisposed to severe asthma and other PAF-mediated disorders. (J. Clin. Invest. 1996. 97:27842791.) Key words: phospholipase $\mathrm{A}_{2}$ • Japanese population • severe asthma $\bullet$ children $\bullet$ inflammation
\end{abstract}

\section{Introduction}

Platelet-activating factor (PAF, 1-O-alkyl-2-acetyl-sn-glycero3 -phosphocholine $)^{1}$ is a biologically active phospholipid with diverse potent biological effects (1-3). PAF has been implicated as a mediator of physiological processes such as signaling and activation of proinflammatory cells, alteration of vascular

Address correspondence to Diana M. Stafforini, Program in Human Molecular Biology and Genetics, Eccles Institute of Human Genetics, University of Utah, Salt Lake City, UT 84112. Phone: 801-5853402; FAX: 801-585-6345; E-mail: diana.stafforini@genetics.utah.edu

Received for publication 9 January 1996 and accepted in revised form 22 March 1996.

1. Abbreviations used in this paper: FISH, fluorescent in situ hybridization; PAF, platelet-activating factor.

J. Clin. Invest.

(C) The American Society for Clinical Investigation, Inc.

0021-9738/96/06/2784/08 \$2.00

Volume 97, Number 12, June 1996, 2784-2791 permeability, and stimulation of glycogen metabolism, among many others (for review see reference 3 ). In addition to its role as a physiological mediator, PAF is associated with the pathology of several human diseases, particularly allergy and inflammation, affecting the respiratory, vascular, digestive and reproductive systems (4). PAF exerts its actions at concentrations as low as $10^{-12} \mathrm{M}$ (1). Its accumulation is tightly regulated at the synthetic and degradative levels to avoid the inappropriately high accumulation of PAF observed in many diseases.

PAF is degraded to inactive products by hydrolysis of the acetyl group at the $s n-2$ position, to produce the biologically inactive products lyso-PAF and acetate. This reaction is catalyzed by PAF acetylhydrolase, a calcium-independent phospholipase $\mathrm{A}_{2}$ specific for hydrolysis of phospholipids containing short and/or oxidized chains at the $s n-2$ position of the glycerol backbone (5-11). Intracellular and plasma PAF acetylhydrolase activities have been described, purified and characterized biochemically (12-15). We recently isolated a cDNA encoding the human plasma PAF acetylhydrolase and showed that the recombinant enzyme abolishes PAF's pathological actions (16). The predicted amino acid sequence of the plasma form of PAF acetylhydrolase contains a Gly-Xaa-SerXaa-Gly motif characteristic of lipases and esterases (16). The serine residue in this conserved motif is essential for activity and it explains the ability of serine esterase inhibitors to abolish enzymatic activity $(16,17)$. Finally, Inoue and co-workers have purified and cloned cDNAs encoding several intracellular PAF acetylhydrolases from bovine brain (18-20).

The levels of PAF acetylhydrolase have been determined in blood from normal human subjects and individuals with a variety of pathological conditions $(3,4)$. Alterations in PAF acetylhydrolase activity have been reported in several disease states and can potentially contribute to the pathogenesis of these conditions (3). For example, acquired deficiency of PAF acetylhydrolase activity has been reported in patients with systemic lupus erythematosus and asthma $(21,22)$, and increased levels of PAF have been reported in children with acute asthmatic attacks (23). In addition to these acquired deficiencies, Miwa et al. described an inherited form of PAF acetylhydrolase deficiency (24). This trait is inherited in an autosomal recessive fashion and has been observed only in the Japanese population (24). Interestingly, the prevalence of this trait is higher in children with severe asthma, suggesting that the decreased ability to degrade PAF allows the phospholipid to accumulate and provoke or amplify the asthmatic response.

To determine the molecular basis of inherited PAF acetylhydrolase deficiency, we amplified all coding exons in the PAF acetylhydrolase gene using DNA isolated from subjects with normal and deficient levels of PAF acetylhydrolase activity. We report the identification of a point mutation near the ac- 
tive site of PAF acetylhydrolase that is present in Japanese subjects with undetectable levels of plasma activity.

\section{Methods}

DNA isolation and exon amplification. Blood was drawn from adult subjects by venipuncture and was anticoagulated with citrate. Epstein-Barr virus-transformed cell lines were established for each subject tested (25). Cells for isolation of total genomic DNA were cultured in RPMI 1640 medium (Cellgrow, Mediatech, Washington, DC) supplemented with $15 \%$ fetal calf serum (Hyclone, Logan, UT). Genomic DNA was isolated by conventional techniques (26) and exon 9 was amplified by the polymerase chain reaction using these genomic DNA samples as templates (27). Typically, the reactions (50 $\mu \mathrm{l})$ contained genomic DNA (100 ng), 50 pmol of each oligonucleotide primer, $200 \mu \mathrm{M}$ each of dCTP, dTTP, dGTP, and dATP, 1.5 $\mathrm{mM} \mathrm{MgCl} 2,10 \mathrm{mM}$ Tris $\left(\mathrm{pH} 8.3\right.$ at $\left.20^{\circ} \mathrm{C}\right), 50 \mathrm{mM} \mathrm{KCl}$, and $2 \mathrm{U}$ of Taq polymerase (Boehringer Mannheim, Indianapolis, IN). Amplifications were performed as follows: first: one cycle at $94^{\circ} \mathrm{C}$ for $5 \mathrm{~min}$; second: 5 cycles at $94^{\circ} \mathrm{C}(60 \mathrm{~s}), 56-60^{\circ} \mathrm{C}(60 \mathrm{~s})$ and $72^{\circ} \mathrm{C}(60 \mathrm{~s})$; third: 30 cycles at $94^{\circ} \mathrm{C}(30 \mathrm{~s}), 52-56^{\circ} \mathrm{C}(30 \mathrm{~s})$ and $72^{\circ} \mathrm{C}(30 \mathrm{~s})$; fourth: one cycle at $72^{\circ} \mathrm{C}(5 \mathrm{~min})$. Primers for amplification across exons $2-12$ were as follows (lower case lettering depicts additional primer sequence added to generate restriction sites for cloning of PCR products):

Sense primer 2: 5'-ccggaattccggTTTCTTGATTTGTCAGCTTA-3' Antisense primer 2: 5' -cgcggatccgcgCAACTTCTTGGGGCCCACTTG-3' Sense primer 3: 5' -ggggtaccccGCATAATAAAATCTGATATG-3' Antisense primer 3: 5' -cgcggatccgcgCTTCTAGTGGTCCATAGCG-3' Sense primer 4: 5' -ccggaattccggCGAAAATAGCTGCTGGAATA-3 Antisense primer 4: 5' 'ggggtacccAGTTCTTGTTGTTTTCAAGG-3' Sense primer 5: 5'-ggggtacccGATGGGTCTGCATTTTATGC-3' Antisense primer 5: 5' -cgcggatccgcgGCATGACATTCCAAACTCTG-3' Sense primer 6: 5' -ccggaattccggCAGTTTTATTAGTGACTCAG-3' Antisense primer 6: 5' -cgcggatccgcgGACATTCCCTGTAGTTGG-3' Sense primer 7: 5'-ggggtaccGAACTGAGAAACATGGTCAG-3' Antisense primer 7: 5' -cgcggatccgcgTAGGAGCATAACTTGCCAGG-3 Sense primer 8: 5' -ccggaattccggAAACTTTAAAATAAGTGTTA-3' Antisense primer 8: 5' -cgcggatccgcgCTGTACTGCTTTGTGTGTC-3' Sense primer 9: 5' -cgcggatccCTATAAATTTATATCATGCT-3' Antisense primer 9: 5'-cggaattcTTTACTATTCTCTTGCTTTAC-3'

Sense primer 10: 5' -ggggtaccccATTAGGATGTCCTCAATGTTGG-3' Antisense primer 10: 5' -cgcggatccgcgAGTTACCAAATGATATCG-3'

Sense primer 11: 5' -ccggaattccggAGACCAACAAGACCAGTACC-3' Antisense primer 11: 5' -cgcggatccgcgTTCAAATTGATATACTGC-3'

Sense primer 12: 5' -ccggaattccggCACATCGTCTCTACCATCC-3' Antisense primer 12: 5' -cgcggatccgcgGGGAAAATACATTAAAATTC-3'

The PCR products were purified and subcloned after digestion with the appropriate restriction enzymes into pBluescript II SK(+) (Stratagene, La Jolla, CA) or by blunt end ligation, as described (28).

Human chromosome mapping. DNA from 25 well-characterized human/rodent somatic cell hybrids was purchased from Coriell Cell Repositories (Camden, NJ). PCR was performed using $100 \mathrm{ng}$ of DNA from each hybrid cell line, in a total volume of $40 \mu \mathrm{l}$. PCR of human, hamster, and mouse control DNAs revealed the presence of a 900-bp product only in the human DNA amplification. The primers used were as follows:

Sense primer I: 5'-GACCTGGCATCTCATGG-3' Antisense primer I: 5'-ACCTCTCCTTTCACTGC-3'

Amplifications were performed as follows: first, one cycle at $94^{\circ} \mathrm{C}$ for $5 \mathrm{~min}$; second, 5 cycles at $94^{\circ} \mathrm{C}(60 \mathrm{~s}), 60^{\circ} \mathrm{C}(60 \mathrm{~s})$ and $72^{\circ} \mathrm{C}(60 \mathrm{~s})$; third, 30 cycles at $94^{\circ} \mathrm{C}(30 \mathrm{~s}), 56^{\circ} \mathrm{C}(30 \mathrm{~s})$ and $72^{\circ} \mathrm{C}(30 \mathrm{~s})$; and fourth, one cycle at $72^{\circ} \mathrm{C}(5 \mathrm{~min})$.

FISH analysis was performed by Dr. Art Brothman at the Molecular Cytogenetics Core Laboratory of the University of Utah. A P1 clone was used as the hybridization probe.

Sequence analysis. Sequencing was performed on plasmid subclones isolated from $E$. coli cultures by the alkaline lysis method. Sequencing of double stranded DNA templates was carried out using the dideoxy chain termination method (29) using the Sequenase 2.0 kit (U.S. Biochemicals, Cleveland, $\mathrm{OH}$ ).
MaeII studies. The PCR products obtained using exon 9 primers (see above) were precipitated and the pellets resuspended in 20-40 $\mu \mathrm{l}$ $\mathrm{H}_{2} \mathrm{O}$. The samples were divided in two identical aliquots: one was treated with MaeII (Boehringer Mannheim, $2 \mathrm{U}$ ) for $3 \mathrm{~h}$ at $50^{\circ} \mathrm{C}$ in a total volume of $25 \mu \mathrm{l}$, following the specifications of the manufacturer. The other aliquot was not digested with MaeII. The digestion products then were subjected to electrophoresis on a 3\% Metaphor $^{\mathrm{TM}}$-agarose gel (FMC BioProducts, Rockland, ME), using a 100bp DNA ladder (GIBCO-BRL, Gaithersburg, MD) as molecular weight standard.

Site-directed mutagenesis. PAF acetylhydrolase was expressed in E. coli, as described (16). The construct for bacterial expression begins with Ile 42 inserted with the trp promoter and a translational start codon into the multiple cloning site of pUC19 (16). The construct harboring the appropriate mutation was prepared by sequential PCR, as follows. Two sets of primers were synthesized. The first set consisted of the following primers:

Sense primer I: 5'-tattctagaattatgATACAAGTACTGATGGCTGCTGCAAG-3' Antisense primer I: 5'-GAATAAACGTTGCTCCAC-3'

The second set of primers was:

Sense primer II: 5'-CAACGTTTATTCAGACTC-3' Antisense primer II: 5' -gcaccatggagtaTAATTGTATTTCTCTATTCCTG-3'

The initial set of reactions $(100 \mu \mathrm{l})$ contained DNA (10 ng of the above construct), $10 \mathrm{pmol}$ of each oligonucleotide primer, $200 \mu \mathrm{M}$ each of dCTP, dTTP, dGTP, and dATP, $1.5 \mathrm{mM} \mathrm{MgCl}_{2}, 10 \mathrm{mM}$ Tris $\left(\mathrm{pH} 8.3\right.$ at $20^{\circ} \mathrm{C}$ ), $50 \mathrm{mM} \mathrm{KCl}$, and $4 \mathrm{U}$ of Taq polymerase (Boehringer Mannheim). Amplifications were performed as follows: first: one cycle at $94^{\circ} \mathrm{C}$ for $5 \mathrm{~min}$; second: 25 cycles at $94^{\circ} \mathrm{C}(45 \mathrm{~s}), 50^{\circ} \mathrm{C}(2$ $\min )$ and $72^{\circ} \mathrm{C}(2 \mathrm{~min})$; third: one cycle at $72^{\circ} \mathrm{C}(10 \mathrm{~min})$. The products were analyzed by electrophoresis on a $1 \%$ SeaPlaque ${ }^{\circledR}$ GTG $^{\circledR}$ Agarose (FMC BioProducts) and had the predicted sizes (733 and $509 \mathrm{bp}$ for the first and second sets of primers, respectively). The next step consisted of amplification using both products obtained above, as templates (1-10 ng each) and sense primer I plus antisense primer II. The rest of the conditions were as described above. A 1230-bp product was obtained, purified as above and digested with $\mathrm{XbaI}$ and KpnI. This DNA was inserted into pUC 19 that had been modified for expression in bacteria, as described (16). Sequence analysis revealed that the mutant had the desired $\mathrm{G} \rightarrow \mathrm{T}$ substitution at position 994.

Genotype determination. Genotypes were determined by three independent amplifications. Genomic DNA (100 ng) was used as template in PCR reactions $(15 \mu \mathrm{l})$ containing $1.5 \mathrm{pmol}$ of each oligonucleotide primer, $200 \mu \mathrm{M}$ each of dCTP, dTTP, dGTP, and dATP, $1.5 \mathrm{mM} \mathrm{MgCl}_{2}, 10 \mathrm{mM}$ Tris $\left(\mathrm{pH} 8.3\right.$ at $\left.20^{\circ} \mathrm{C}\right), 50 \mathrm{mM} \mathrm{KCl}$, and $0.6 \mathrm{U}$ of Taq polymerase (Boehringer Mannheim). The sense primer (Sense primer A) was the same for all reactions, and three antisense primers (B, C, and D) were synthesized for this study:

Sense primer A: 5'-CTATAAATTTATATCATGCTT-3' Antisense primer B: 5'-TTTACTATTCTCTTGCTTTAC-3' Antisense primer C: 5'-TCACTAAGAGTCTGAATAAC-3' Antisense primer D: 5'-TCACTAAGAGTCTGAATAAA-3'

Amplifications were performed as follows: first, one cycle at $94^{\circ} \mathrm{C}$ for $5 \mathrm{~min}$; second, 5 cycles at $94^{\circ} \mathrm{C}(60 \mathrm{~s}), 56^{\circ} \mathrm{C}(60 \mathrm{~s})$ and $72^{\circ} \mathrm{C}(60 \mathrm{~s})$; third, 25 cycles at $94^{\circ} \mathrm{C}(30 \mathrm{~s}), 52^{\circ} \mathrm{C}(30 \mathrm{~s})$ and $72^{\circ} \mathrm{C}(30 \mathrm{~s})$; and fourth, one cycle at $72^{\circ} \mathrm{C}(5 \mathrm{~min})$. The sizes of the products formed were: 160 bp when primers A and B were used, and 108 bp otherwise. The products were analyzed by electrophoresis on a $3 \%$ Metaphor $^{\circledR}$-Agarose (FMC BioProducts).

Activity assays. PAF acetylhydrolase activity was determined as described (30).

\section{Results}

Structure and organization of the PAF acetylhydrolase gene. We first determined the organization of the PAF acetylhydro- 


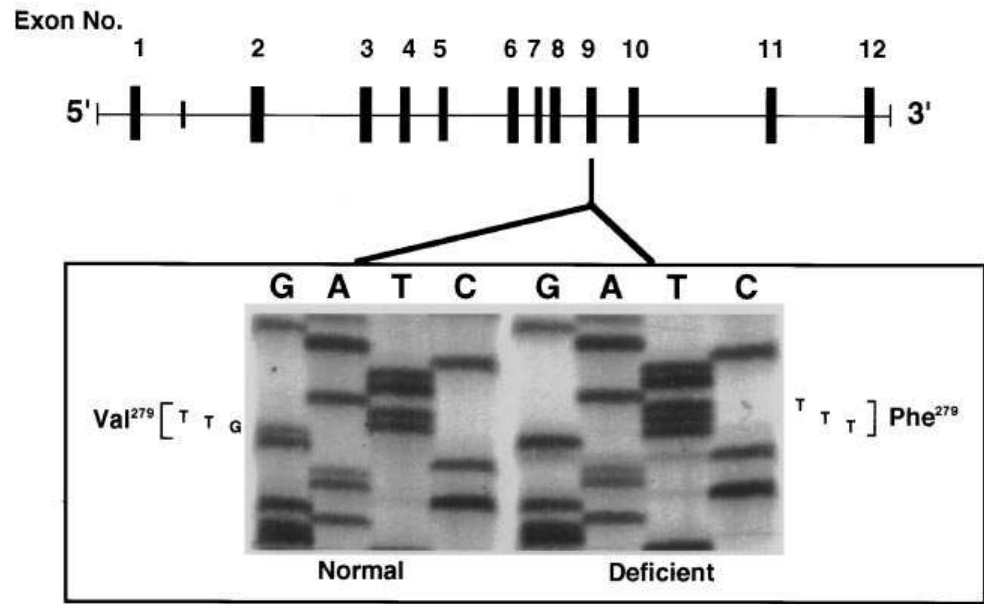

B

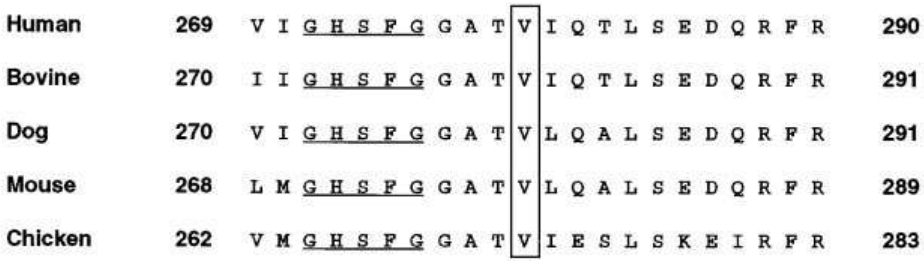

Figure 1. A G $\rightarrow$ T substitution is present in subjects deficient in PAF acetylhydrolase activity. This point mutation results in a $\mathrm{Val} \rightarrow$ Phe transversion in a region highly conserved within mammals. A (top) illustrates the genomic organization of the PAF acetylhydrolase gene. The bottom section is an autoradiography of a DNA sequencing gel showing the PAF acetylhydrolase sequence isolated from a Caucasian subject with normal levels of plasma activity (left). The right panel displays the sequence derived by amplification of DNA from a Japanese subject deficient in the plasma activity. The $\mathrm{G} \rightarrow \mathrm{T}$ substitution results in a Val $\rightarrow$ Phe transversion at position 279 of the mature protein. (B) Amino acid sequence alignment of PAF acetylhydrolase from multiple species, near valine 279. The boxed area shows that the valine residue ( $\mathrm{val}^{279}$ in the human protein) is highly conserved among species (17). The underlined residues are highly conserved in lipases and esterases; this area includes the active site serine (16, 17). Numbers indicate starting (left) and ending (right) positions of the segments shown. lase gene by isolating three human genomic clones containing PAF acetylhydrolase sequences in bacteriophage $\mathrm{P} 1$ and $\lambda$ vectors (Fig. $1 A$ ). We determined the restriction map of the insert sequences for several restriction enzymes (e. g., BglII, SacI, XbaI, EcoRI, BamHI, and HindIII) and subcloned restriction fragments corresponding to cDNA sequences. We then designed sense and antisense cDNA primers, to obtain sequence information of exonic and flanking regions.

The PAF acetylhydrolase gene is organized in 12 exons spanning at least $45 \mathrm{~kb}$ of DNA sequence. The first exon encodes $127 \mathrm{nt}$ of $5^{\prime}$-untranslated sequence (Table I). Exon 2 encodes 34 additional nt of $5^{\prime}$-untranslated sequence, coding sequence for the putative signal peptide (17 amino acid residues), and the first 19 amino acid residues of the mature protein (16). Exons 3 through 12 contain the remaining coding sequence, beginning within the codon for the 20th amino acid of the mature protein and ending within the translational stop codon. The average exon size was $129 \mathrm{bp}$ and the splice junctions agree favorably with consensus splice sites for mammalian genes (26).

Chromosomal localization of the PAF acetylhydrolase gene. To determine the chromosomal location of the human plasma PAF acetylhydrolase gene, we used a panel of human/ rodent DNA hybrids from the NIGMS (somatic cell mapping panel No. 2) and primers localized in exon 6 (sense) and intron 7 (antisense). Products $(\sim 900 \mathrm{bp})$ were obtained from human

Table I. Exon Sizes and Sequence at Intron/Exon Boundaries of the PAF Acetylhydrolase Gene

\begin{tabular}{|c|c|c|c|c|c|}
\hline Exon & $5^{\prime}$ Intron & & $3^{\prime}$ Intron & Exon length & $\begin{array}{c}\text { Amino acids } \\
\text { encoded }\end{array}$ \\
\hline & & & & base pairs & \\
\hline 1 & tcggcccgcagccagggggacagcg & GCTG.....GCTG & gaggtcgggaccccggagcgcgacc & 127 & 0 \\
\hline 2 & tttctttaatcatctgcttcgaag & GAGA..... T CAG & gtaagaggtgtatttgttcaaggtc & 143 & 36 \\
\hline 3 & gagataatattacctgttttcag & CATG..... TAAG & gtaatgcttgatttatacaactta & 122 & 41 \\
\hline 4 & aagtccattaattcttcttaacag & GGCA.... T T T G & gtaagattetgttgatccttctt & 145 & 48 \\
\hline 5 & actataaccttccattgttgtctag & GT T C..... T CAG & gtaatgtttgagaggttgaacaat $t$ & 94 & 32 \\
\hline 6 & attcttccetctttgtttgaag & GACA......ACAG & gtacattgcagtgaaaggagaggtg & 69 & 23 \\
\hline 7 & ataaataatttgcttgtattatag & AGAT.....GCAG & gtacattgcagtgaaaggagaggtg & 124 & 41 \\
\hline 8 & ttccttcttctaataat tatag & GTAC.....GAAG & gtaagctataaaaagtaattttct & 114 & 38 \\
\hline 9 & atttatatcatgcttttcaaatag & GACT..... TCAG & gtaagaaaataagatagtaaagtaa & 92 & 31 \\
\hline 10 & catcattgtcaacaaatatctacag & ATGT.... T CAG & gtaagtattagtgact tatt tcat $t$ & 171 & 57 \\
\hline 11 & tttaalgtcttgttctctttag & GGGT.... T T AG & gtaagaaactattttttcatgacc & 149 & 49 \\
\hline 12 & ttgattaacactttatatttatag & GACT .....AAAA & gtctgtttcaaaactgtctaaaat & 159 & 45 \\
\hline
\end{tabular}

Exon and intron sequences are shown in upper- and lowercase letters, respectively. 
genomic DNA, but not from mouse or hamster DNAs (Fig. 2 $A$, lanes $A-C$ ), as expected. In addition, products were obtained from DNA templates harboring human chromosomes 1 and 6 (Fig. $2 \mathrm{~A}$, lanes 1 and 6 ). To precisely establish the location of the PAF acetylhydrolase gene, we performed FISH analysis using a P1 clone obtained previously (Fig. $1 A$ ). Positive hybridization signals were observed at chromosome $6 \mathrm{p} 12$ 21.1 on both chromosomes (Fig. $2 B$ ). The band assignment for FISH signals was determined by sequential FISH after G-banding. No signals were detected on chromosome 1, suggesting that the PCR products obtained using the rodent/human hybrid panel were nonspecific.

Identification of a point mutation in a PAF acetylhydrolase deficient subject. We analyzed DNA from an affected member of a Japanese family with inherited plasma PAF acetylhydrolase deficiency, as determined by the biochemical assay. DNA from a subject with normal enzymatic activity was tested simultaneously. We amplified genomic DNA from either defi- cient or normal subjects using primers designed from intronic sequences to the $5^{\prime}$ and $3^{\prime}$ of each coding exon (see Methods). These reactions yielded PCR products for each individual coding exon (not shown). In addition, the size of individual PCR products obtained from normal and deficient subjects was the same as determined by agarose gel electrophoresis (data not shown). These results ruled out the possibility that translocations, insertions or deletions accounted for PAF acetylhydrolase deficiency in this family, since these would have resulted in either no amplification, an increase or decrease in the size of the product, respectively. Thus, we considered the possibility that a point mutation was responsible for PAF acetylhydrolase deficiency. We used single stranded conformational polymorphism (SSCP), precise size determination on sequencing gels, and sequence analyses to detect alterations in the conformation and/or small size variations of exons obtained from deficient subjects. These studies resulted in the identification of polymorphisms that did not account for the observed defi-

A

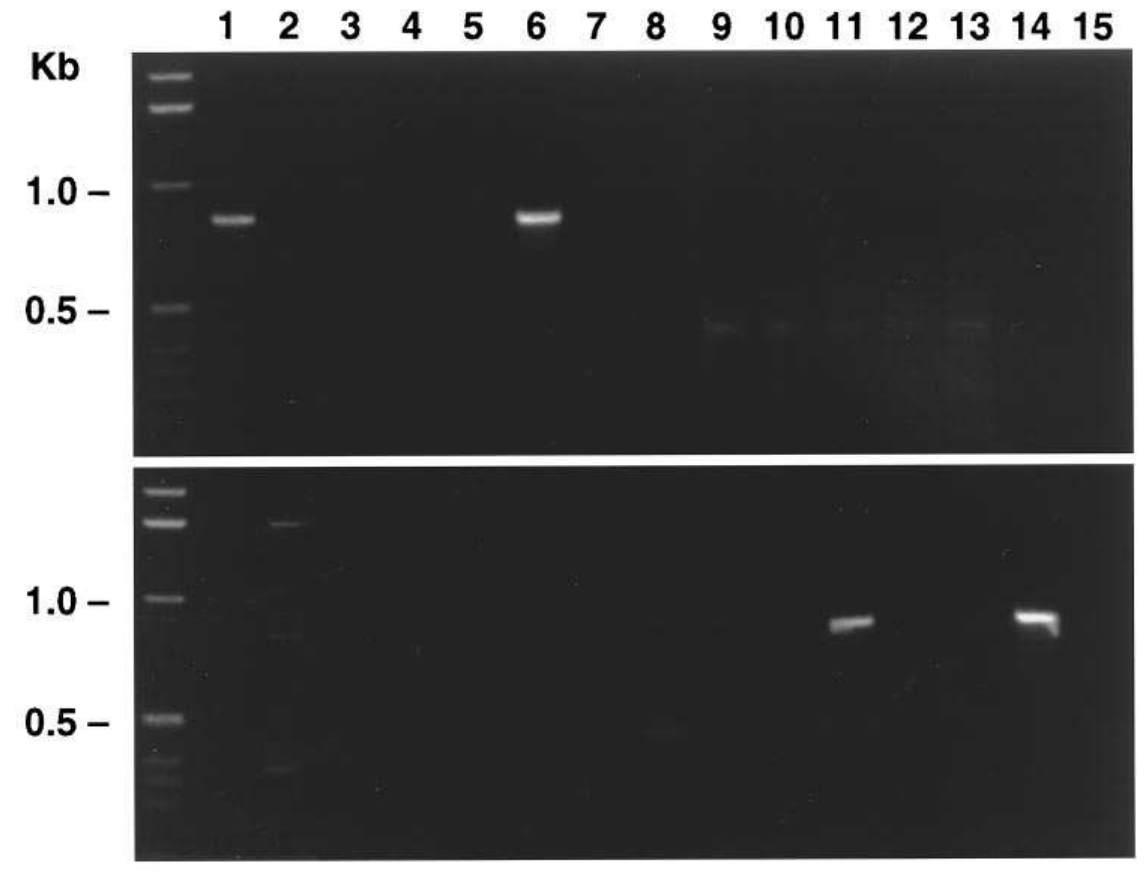

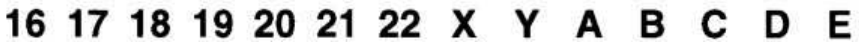

B

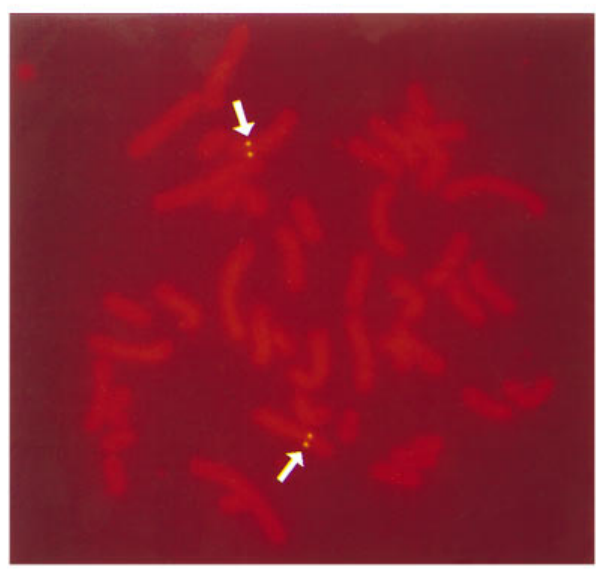

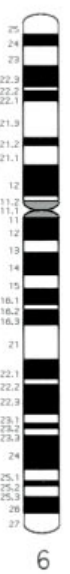

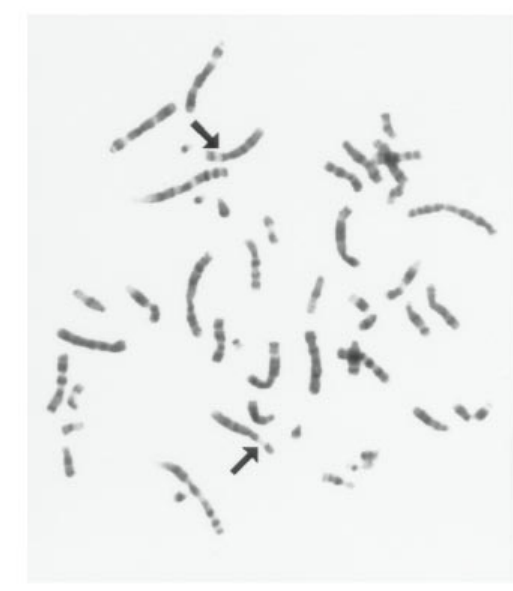

Figure 2. The human PAF acetylhydrolase gene is located in chromosome 6p12-21.1. $A$ shows the PCR products obtained using a rodent/human hybrid panel of DNA samples containing human chromosomes 1-22, $\mathrm{X}$, and $\mathrm{Y}$. The numbers shown correspond to reactions in which the template contained the corresponding human chromosome. Genomic DNA samples from hamster (A), human (B) and mouse (C) cells were used in lanes $A-C$. Lanes $D$ and $E$ represent negative and positive controls, respectively. $B$ depicts the determination of chromosomal localization by FISH analysis. A representative metaphase preparation is shown to indicate the position of the PAF acetylhydrolase gene (left). The banded chromosome 6 is shown together with a schematic idiogram to indicate that the PAF acetylhydrolase gene probe hybridizes to band 6p12-21.1 (right). 
ciency in enzymatic activity because they occurred in non-coding regions of the gene (not shown).

Our next approach consisted in sequencing multiple clones of amplified exons derived from normal and deficient subjects. These studies revealed a single point mutation, a $\mathrm{G} \rightarrow \mathrm{T}$ transversion, at position 994 in the ninth exon, which contains the active site $(16,17)$. This nucleotide change results in a nonconservative $\mathrm{Val} \rightarrow$ Phe substitution at residue 279 of the mature PAF acetylhydrolase (Fig. $1 A$ ). $\mathrm{Val}^{279}$ is conserved in plasma PAF acetylhydrolases from different species (human, mouse, dog, cow, and chicken; Fig. $1 B$ and reference 17) which suggests that it may be essential. In addition, PAF acetylhydrolase contains a Ser-Asp-His catalytic triad at the active site (17) and $\mathrm{Val}^{279}$ lies between the active site ser and asp residues in a region that likely is critical for proper folding of the enzyme. These results suggested that the transition of $\mathrm{Val}^{279}$ to Phe could account for the lack of enzymatic activity in this family.

Cosegregation of PAF acetylhydrolase activity and the point mutation. The $\mathrm{G} \rightarrow \mathrm{T}$ transversion generates a new restriction site for MaeII (Fig. 3 A) and we used this to test whether the enzymatic deficiency and the $\mathrm{G} \rightarrow \mathrm{T}$ mutation cosegregate in four Japanese families available for testing (Fig. 3 B). The size of exon 9 amplified from subjects with normal PAF acetylhydrolase levels was not modified by MaeII digestion. However, DNA amplified from completely deficient subjects always gave two fragments (82 and $95 \mathrm{bp}$ in length) when incubated with MaeII. Further, DNA from subjects characterized as heterozygous on the basis of a $50 \%$ decrease in plasma PAF acetylhydrolase activity had three fragments $(82,95$, and 177 bp) after MaeII digestion indicating one normal and one mutant allele. Thus, the results from these small families were consistent with the interpretation that the $\mathrm{Val}^{279} \rightarrow$ Phe mutation accounts for PAF acetylhydrolase deficiency.

A single mutation accounts for PAF acetylhydrolase deficiency in all subjects tested. To expand this analysis of the significance of the $\mathrm{Val}^{279} \rightarrow$ Phe mutation, we tested an additional 41 Japanese subjects deficient in PAF acetylhydrolase activity. They were identified by enzymatic assay using plasma obtained from a random population of individuals participating in an annual screening examination. Exon 9 was amplified from genomic DNA of each subject, and the products were digested with MaeII and analyzed by electrophoresis (not shown). In all cases, the initial product (177 bp) was completely digested to 82 and $95 \mathrm{bp}$ fragments by MaeII. Thus, all of the randomly selected deficient subjects had the suspected mutation. In contrast, this pattern was never observed in 84 individuals from the same population who had detectable enzymatic activity. These results indicate that the deficiency in PAF acetylhydrolase activity and the $\mathrm{Val}^{279} \rightarrow$ Phe transition cosegregate, and that a single mutation may account for all such deficiency in Japan.

The $\mathrm{Val}^{279} \rightarrow$ Phe transition accounts for the lack of enzymatic activity in PAF acetylhydrolase deficient subjects. To examine the functional significance of the $\mathrm{Va}^{279} \rightarrow$ Phe mutation, we expressed the normal and mutant cDNAs in E. coli (Fig. 4). As shown by immunoreactivity, PAF acetylhydrolase protein was expressed to the same level by bacteria transformed with the normal and mutant constructs. However, the normal construct yielded a protein with enzymatic activity while the $\mathrm{Phe}^{279}$ construct resulted in inactive protein. This result indicates that the $\mathrm{Val}^{279} \rightarrow$ Phe mutation abolishes the enzymatic
A

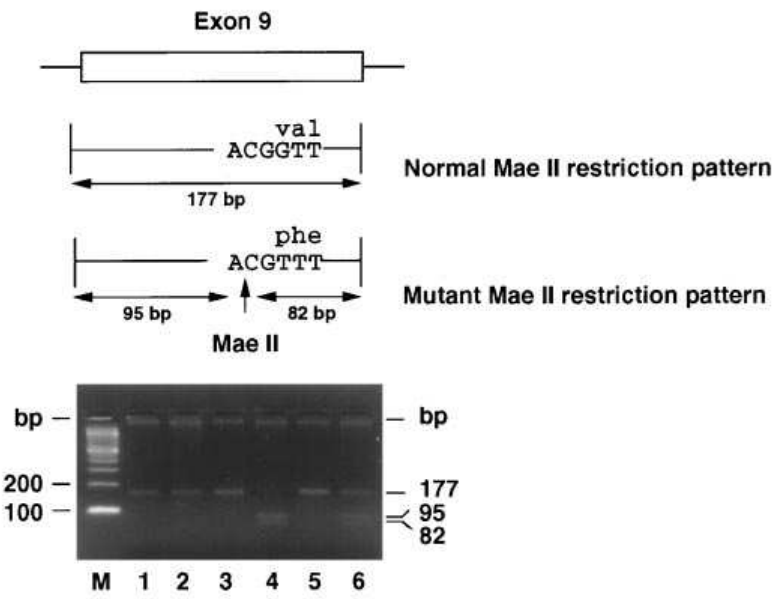

B
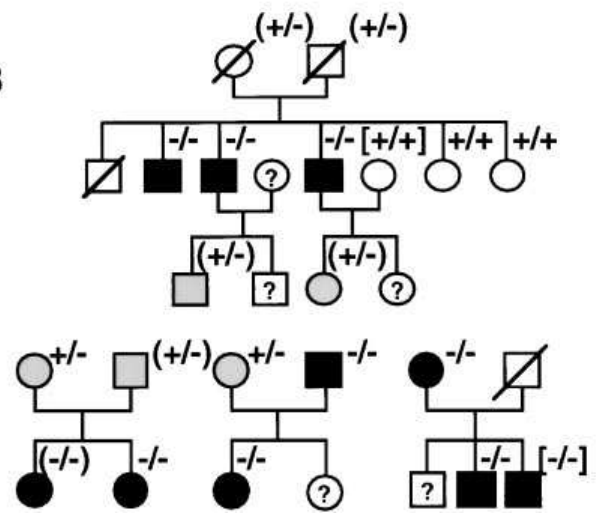

Figure 3. The $\mathrm{G} \rightarrow \mathrm{T}$ transition at position 994 of the PAF acetylhydrolase cDNA generates a new MaeII restriction site; this new site was used to test whether PAF acetylhydrolase deficiency cosegregates with the mutation. $A$ shows the expected MaeII restriction pattern of PCR-amplified exon 9 of DNA samples isolated from individuals with the normal and mutant allele. The agarose gel on the bottom illustrates the size of undigested PCR-amplified exon 9 from subjects with deficient (lane 1), normal (lane 2), and intermediate (lane 3) levels of PAF acetylhydrolase activity, and DNA from each source after digestion with MaeII (lanes 4, 5, and 6, respectively). For illustrative purposes we show the results obtained from one subject of each category, but this test was applied to all family members from whom DNA samples were available. $B$ shows four Japanese pedigrees with PAF acetylhydrolase deficiency. Individuals having no detectable plasma PAF acetylhydrolase activity are represented by black circles (females) and black squares (males). Unaffected individuals are represented by open circles (females) and open squares (males). Family members who have intermediate levels of activity are represented by shaded circles (females) and shaded squares (males). Individuals for whom no phenotypic data were available are identified by a question mark (?). Above each symbol, individual alleles are represented by a "+" sign (normal exon 9) and/or a "-" sign (indicates $\mathrm{G} \rightarrow \mathrm{T}$ missense mutation in exon 9). Parentheses indicate that the genotype was predicted based on genetic and biochemical information from family members. PAF acetylhydrolase deficiency cosegregates with the mutation and individuals heterozygous for the mutation have lower activity levels than unaffected subjects. Informed consent was obtained from each family member before inclusion in the study. 
activity of PAF acetylhydrolase and accounts for the deficiency in Japanese subjects. To examine if the mutant protein was expressed in vivo, albeit in inactive form, we subjected plasma from deficient subjects to electrophoresis and Western blotting. We detected no immunoreactive protein in plasma from deficient subjects in contrast to normal plasma which expressed detectable levels of enzyme (Fig. 4, lower panel). Thus, both plasma PAF acetylhydrolase activity and protein are lacking in these individuals.

Frequency of the $G \rightarrow T$ transversion in the Japanese and North American populations. Finally, we examined the allelic frequency of this mutation in the Japanese population. For this experiment we developed a rapid PCR assay that gives discrete products from the normal and mutant alleles and in control experiments showed that it accurately reflects the $\mathrm{G} \rightarrow \mathrm{T}$ transversion at position 994. This assay was developed to reduce the cost and to simplify the screening process. We used
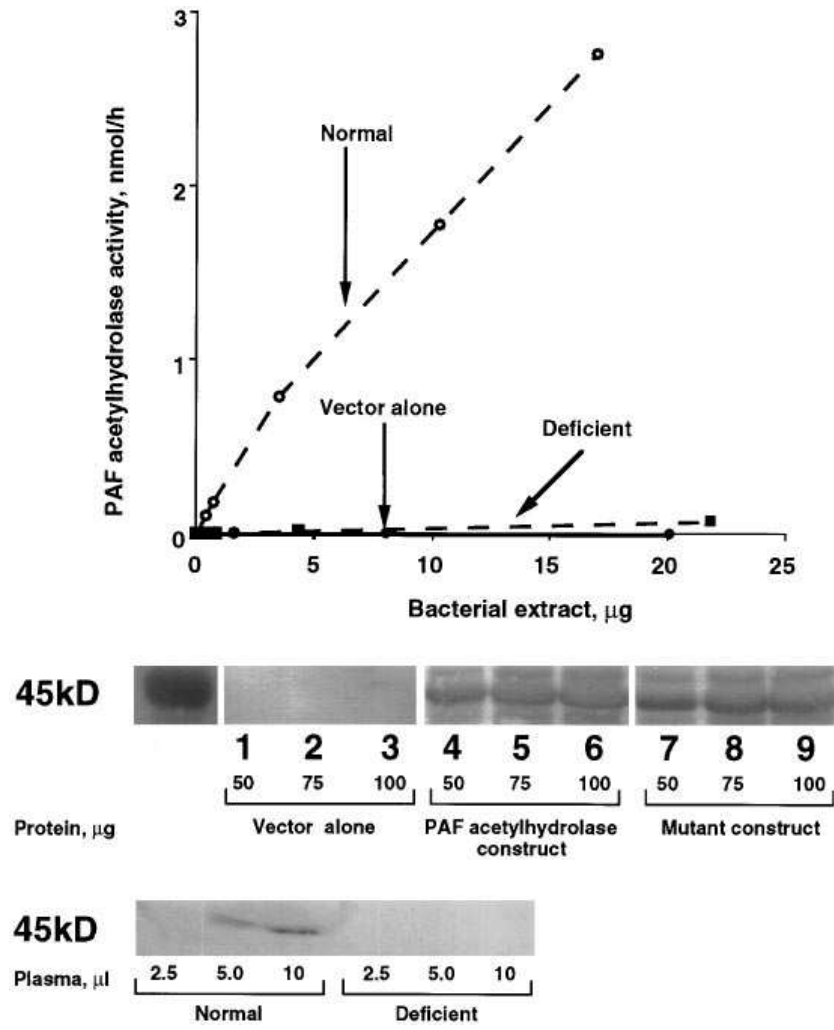

Figure 4. Expression of normal and mutant PAF acetylhydrolase gene: the $\mathrm{G} \rightarrow \mathrm{T}$ transition results in the production of inactive enzyme that can be detected by immunoblotting. Bacteria transformed with the PAF acetylhydrolase construct, the mutant construct and with vector alone were grown for $16 \mathrm{~h}$ at $37^{\circ} \mathrm{C}$, harvested, lysed by sonication, and tested for PAF acetylhydrolase activity (30). Additional aliquots ( $50 \mu \mathrm{g}$ for lanes 1,4, and 7; $75 \mu \mathrm{g}$ for lanes 2, 5, and 8; and $100 \mu \mathrm{g}$ for lanes 3,6 , and 9 ) were subjected to electrophoresis on $10 \%$ acrylamide gels, as described (26). The separated proteins were transferred to a PVDF membrane which was then probed with a rabbit polyclonal antibody against recombinant PAF acetylhydrolase. The blots were developed using alkaline phosphatase-labeled goat anti-rabbit IgG. The bottom panel is Western blot in which normal plasma and PAF acetylhydrolase deficient plasma were subjected to electrophoresis and transferred to a PVDF membrane, as above. The blots were developed using horesradish peroxidase-labeled goat antirabbit $\operatorname{IgG}$ and an enhanced chemiluminescence detection method.
DNA isolated from 127 randomly selected Japanese subjects in specific PCR amplifications using three sets of primers (Fig. $5 A$ ). We also measured their plasma PAF acetylhydrolase activity (Fig. 5 B). The mutant allele was present in $27 \%$ of the Japanese population as heterozygotes and $4 \%$ as homozygotes. This corresponded perfectly with enzyme activity levels (Fig. $5 \mathrm{~B}$ ). In contrast, no heterozygous or homozygous deficient subjects were identified in a random North American population ( $n=108$, not shown). Both Miwa et al. (24) and we found a $4 \%$ prevalence of homozygous deficiency in Japan and our result of a $27 \%$ prevalence of heterozygosity agrees with the allele frequency predicted if the population is in HardyWeinberg equilibrium. We found that heterozygosity is established more conclusively by DNA analysis since enzymatic activity determinations revealed overlap between normal and heterozygous subjects (Fig. $5 \mathrm{~B}$ ). This was expected since we and others have shown that the levels of activity are regulated by environmental factors $(4,21,31)$.

\section{Discussion}

Human plasma PAF acetylhydrolase has potentially crucial physiological and pathological roles because it abolishes the diverse effects of PAF and oxidized phospholipids, which include inflammation and thrombosis. Decreased degradation of these biologically active molecules should result in pathological responses, and acquired PAF acetylhydrolase deficiency has been described in patients with systemic lupus erythematosus (21) and septic shock (32).

The prevalence of asthma and allergic diseases has been reported to be low in Asian populations compared with the United Kingdom and Australia $(33,34)$ while other studies support the notion that the incidence of asthma is higher in Asian ethnic groups than in the White population (35). This contradictory results are likely due to the lack of uniformity in the methodology used to define asthma and the complicated, multifactorial nature of the disease which make it difficult to compare prevalence data between studies (36). Leung and Ho (36) recently reported that family history is the strongest predicting factor for asthma and allergic symptoms in three Asian populations, conferring a 3-80-fold increase in risk to family members, which is significantly higher than the 2-3-fold increase found for Western Countries $(37,38)$. These studies suggest that common genetic factors interact in a complex manner to initiate clinical asthma and allergy. Miwa et al. (24) showed that Japanese children with no detectable plasma PAF acetylhydrolase activity have a high prevalence of severe asthma. The natural history of individuals with PAF acetylhydrolase deficiency is not known since a cohort has not been followed prospectively nor are cross-sectional studies available. We predict that these individuals will have increased severity and incidence of inflammatory and allergic disorders. We propose that the function of plasma PAF acetylhydrolase is analogous to that of other protective plasma proteins such as protein $\mathrm{C}$, which is a protease that suppresses coagulation, and $\alpha-1$ antitrypsin, which inhibits the activity of proteases. Importantly, heterozygous subjects deficient in protein $\mathrm{C}$ show an increased risk of thrombosis when studied as part of a pedigree, but the modest increased risk is not apparent in populationbased studies $(39,40)$. Similarly, patients deficient in $\alpha-1$ antitrypsin often are modestly affected unless they smoke cigarettes, which leads to severe emphysema (41). By analogy, patients 
A
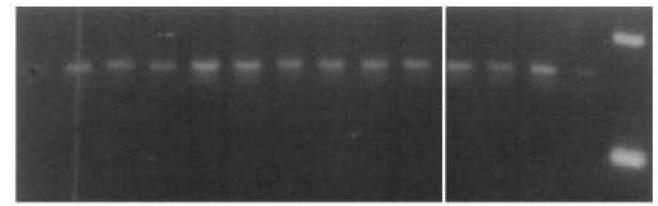

200

Complete exon (positive control)

100
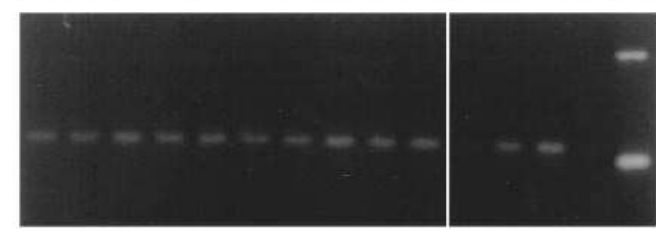

200

Normal allele

100

200

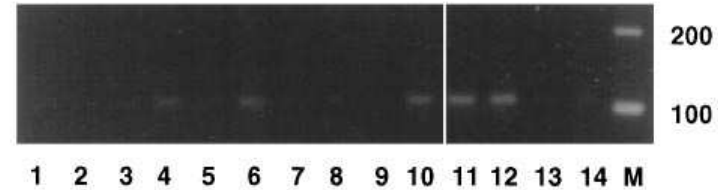

Mutant allele

00

$\begin{array}{lllllllllllllll}2 & 3 & 4 & 5 & 6 & 7 & 8 & 9 & 10 & 11 & 12 & 13 & 14 & M\end{array}$
B

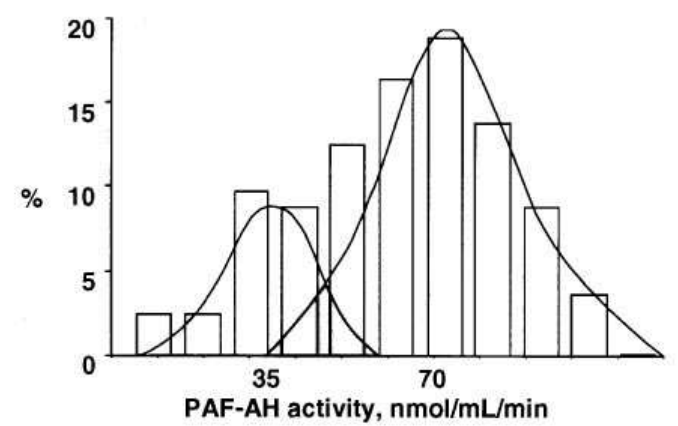

with PAF acetylhydrolase deficiency may be relatively normal unless they develop inflammatory conditions mediated by PAF which would accumulate to high levels and initiate severe inflammation. The high frequency of the mutant allele is intriguing and may reflect a selective advantage in heterozygotes, although this is likely to be true only if it is a relatively ancient mutation.

We report here that the human PAF acetylhydrolase gene is located in chromosome 6p12.p21.1. Other genes have been localized to this region as well. A severe form of polycystic kidney disease maps to chromosome 6p21.1p12 (42). In addition, juvenile myoclonic epilepsy has been recently shown to map to chromosome 6p21.2-p11 (43) and there is evidence that chromosome $6 \mathrm{p}$ carries a locus that predisposes to schizophrenia (44). These findings are interesting as mRNA for plasma PAF acetylhydrolase has been detected in certain regions of the brain (16) and intracellular PAF acetylhydrolase activities have been purified and cloned from bovine brain $(12,13,18$ $20)$. This suggests that PAF and/or related lipids may have important neural signaling functions $(45,46)$ and that PAF acetylhydrolase activity may serve to modulate the actions of PAF and related lipids in the brain. The balance between PAF production and degradation may be an important factor in brain homeostasis and alterations in this balance may lead to human disease.

\section{Acknowledgments}

We thank Dr. Ray White for critical review of this manuscript, Dr. Mark Curran for useful discussions, and E. Padilla and Liping Cheng for excellent technical assistance. The oligonucleotide primers used were synthesized by Dr. Robert Shackmann at the University of Utah Protein-DNA Core Facility. FISH analysis was performed by Dr. Art Brothman at the Molecular Cytogenetics Core Laboratory of the University of Utah.

The work at the University of Utah was supported by grants from the National Institutes of Health (DK-49219 and HL-50153) and the American Heart Association (92023050). Both facilities are supported in part by a grant from the National Cancer Institute (3P30 CA 42014). Drs. Prescott, Zimmerman and McIntyre are consultants for ICOS Corporation.

\section{References}

1. Prescott, S.M., G.A. Zimmerman, and T.M. McIntyre. 1990. Platelet-activating factor. J. Biol. Chem. 265:17381-17384.

2. Snyder, F. 1987. Platelet-activating factor and related lipid mediators. Plenum Press, New York.

3. Zimmerman, G.A., S.M. Prescott, and T.M. McIntyre. 1992. Platelet-activating factor (PAF): a fluid phase and cell-associated mediator of inflammation. In Inflammation: Basic Principles and Clinical Correlates. J.I. Gallin, I.M. Goldstein, and R. Snyderman, editors. Raven Press, New York. 149-176.

4. Imaizumi, T.-a., D.M. Stafforini, Y. Yamada, T.M. McIntyre, S.M. Prescott, and G.A. Zimmerman. 1995. Platelet-activating factor: a mediator for clinicians. J. Int. Med. 238:5-20.

5. Farr, R.S., C.P. Cox, M.L. Wardlow, and R. Jorgensen. 1980. Preliminary studies of an acide-labile factor (ALF) in human sera that inactivates plateletactivating factor (PAF). Clin. Immunol. Immunopathol. 15:318-330.

6. Blank, M.L., T.-c. Lee, V. Fitzgerald, and F. Snyder. 1981. A specific acetylhydrolase for 1-alkyl-2-acetyl-sn-glycero-3-phopshocholine (a hypotensive and platelet-activating lipid). J. Biol. Chem. 256:175-178.

7. Lee, T.-c., B. Malone, S.I. Wasserman, V. Fitzgerald, and F. Snyder. 1982. Activities of enzymes that metabolize platelet-activating factor (1-alkyl-2acetyl-sn-glycero-3-phosphocholine) in neutrophils and eosinophils from humans and the effect of a calcium ionophore. Biochem. Biophys. Res. Commun. 105:1303-1308. 
8. Stafforini, D.M., T.M. McIntyre, M.E. Carter, and S.M. Prescott. 1987. J. Biol. Chem. 262:4215-4222.

9. Stremler, K.E., D.M. Stafforini, S.M. Prescott, G.A. Zimmerman, and T.M. McIntyre. 1989. An oxidized derivative of phosphatidylcholine is a substrate for the platelet-activating factor acetylhydrolase from human plasma. $J$. Biol. Chem. 264:5331-5334.

10. Yanoshita, R., I. Kudo, K. Ikizawa, H.W. Chang, S. Kobayashi, M. Ohno, S. Nojima, and K. Inoue. 1988. Hydrolysis of platelet-activating factor and its methylated analogs by acetylhydrolases. J. Biochem. 103:815-819.

11. Stafforini, D.M., S.M. Prescott, G.A. Zimmerman, and T.M. McIntyre. 1991. Platelet-activating factor acetylhydrolase activity in human tissues and blood cells. Lipids. 26:979-985.

12. Hattori, M., H. Adachi, M. Tsujimoto, H. Arai, and K. Inoue. 1994. The catalytic subunit of bovine brain platelet-activating factor acetylhydrolase is a novel type of serine esterase. J. Biol. Chem. 269:23150-23155.

13. Hattori, M., H. Arai, and K. Inoue. 1993. Purification and characterization of bovine brain platelet-activating factor acetylhydrolase. J. Biol. Chem. 268:18748-18753.

14. Stafforini, D.M., E.N. Rollins, S.M. Prescott, and T. M. McIntyre. 1993. The platelet-activating factor acetylhydrolase from human erythrocytes. Purification and properties. J. Biol. Chem. 268:3857-3865.

15. Stafforini, D.M., S.M. Prescott, and T.M. McIntyre. 1987. Human plasma platelet-activating factor acetylhydrolase. Purification and properties. J. Biol. Chem. 262:4223-4230.

16. Tjoelker, L.W., C. Wilder, C. Eberhardt, D.M. Stafforini, G. Dietsch, B. Schimpf, S. Hooper, H.L. Trong, L.S. Cousens, G.A. Zimmerman, Y. Yamada, T. M. McIntyre, S.M. Prescott, and P.W. Gray. 1995. Anti-inflammatory properties of a platelet-activating factor acetylhydrolase. Nature (Lond.). 374: 549552 .

17. Tjoelker, L.W., C. Eberhardt, J. Unger, H.L. Trong, G.A. Zimmerman, T.M. McIntyre, D.M. Stafforini, S.M. Prescott, and P.W. Gray. 1995. Plasma platelet-activating factor acetylhydrolase is a secreted phjospholipase $\mathrm{A}_{2}$ with a catalytic triad. J. Biol. Chem. 270:25481-25487.

18. Hattori, M., H. Adachi, J. Aoki, M. Tsujimoto, H. Arai, and K. Inoue. 1995. Cloning and expression of a cDNA encoding the $\beta$-subunit (30 KDa Subunit) of bovine brain platelet-activating factor acetylhydrolase. J. Biol. Chem. 270:31345-31352.

19. Hattori, M., H. Adachi, M. Tsujimoto, H. Arai, and K. Inoue. 1994. Miller-Dieker lissencephaly gene encodes a subunit of brain platelet-activating factor acetylhydrolase. Nature (Lond.). 370:216-218.

20. Hattori, M., K. Hattori, H. Adachi, M. Tsujimoto, H. Arai, and K. Inoue. 1995. Purification and characterization of platelet-activating factor acetylhydrolase II from bovine brain liver cytosol. J. Biol. Chem. 270:22308-22313.

21. Tetta, C., F. Bussolino, V. Modena, G. Montrucchio, G. Segoloni, G. Pescarmona, and G. Camussi. 1990. Release of platelet-activating factor in systemic lupus erythematosus. Int. Arch. Allergy Appl. Immunol. 91:244-256.

22. Tsukioka, K., M. Matsuzaki, M. Nakamata, and H. Kayahara. 1993. Increased plasma levels of platelet-activating factor (PAF) and low serum PAF acetylhydrolase (PAF-AH) activity in adult patients with bronchial asthma. Arerugi. 42:167-171.

23. Hsieh, K.-H., and C.-K. Ng. 1993. Increased plasma platelet-activating factor in children with acute asthmatic attacks and decreased in vivo and in vitro production of platelet-activating factor after immunotherapy. J. Allergy Clin. Immunol. 91:650-657.

24. Miwa, M., T. Miyake, T. Yamaoka, J. Sugatani, Y. Suzuki, S. Sakata, Y. Araki, and M. Matsumoto. 1988. Characterization of serum platelet-activating factor (PAF) acetylhydrolase: correlation between deficiency of serum PAF acetylhydrolase and respiratory symptoms in asthmatic children. J. Clin. Invest. 82:1983-1991.

25. Kunkel, L.M., K.D. Smith, S.H. Boyer, D.S. Borgaonkar, S.S. Wachtel, O.J. Miller, W.R. Breg, H.W. Jones, and J.M. Rary. 1977. Analysis of human
Y-chromosome specific reiterated DNA in chromosome variants. Proc. Natl. Acad. Sci. USA. 74:1245-1249.

26. Sambrook, J., E.F. Frilsch and I. Maniatis. 1982. Molecular Cloning: a Laboratory Manual. Cold Spring Harbor, New York, Cold Spring Harbor Laboratory Press.

27. Saiki, R.K., D.H. Gelfand, S. Stoffel, S.J. Scharf, R. Higuchi, G.T. Horn, K.B. Mullis, and H.A. Erlich. 1988. Primer-directed enzymatic amplification of DNA with a thermostable DNA polymerase. Science (Wash. DC). 239:487-491.

28. Marchuk, D., M. Drumm, A. Saulino, and F.S. Collins. 1991. Construction of T-vectors, a rapid and general system for direct cloning of unmodified PCR products. Nucleic Acids Res. 19:1154.

29. Sanger, F., S. Nicklen, and A.R. Coulson. 1977. DNA sequencing with chain-terminating inhibitors. Proc. Nat. Acad. Sci. USA. 74:5463-5467.

30. Stafforini, D. M., T. M. McIntyre, and S. M. Prescott. 1990. Platelet-activating factor acetylhydrolase from human plasma. Methods Enzymol. 187:344357.

31. Miyaura, S., H. Eguchi, and J.M. Johnston. 1992. Effect of a cigarette smoke extract on the metabolism of the proinflammatory autacoid, plateletactivating factor. Circ. Res. 70: 341-347.

32. Graham, R.M., C.J. Stephens, W. Silvester, L.L. Leong, M.J. Strurm, and R.R. Taylor. 1994. Plasma degradation of platelet-activating factor in severely ill patients with clinical sepsis. Crit. Care Med. 22:204-212.

33. Ninan, T.K., and G. Russell. 1992. Respiratory symptoms and atopy in Aberdeen schoolchildren: evidence from two surveys 25 years apart. Br. Med. J. 304:873-875.

34. Robertson, C.F., E. Heycock, J. Bishop, T. Nolan, A. Olinsky, and P.D.

Phelan. 1991. Prevalence of asthma in Melbourne schoolchildren: change over 26 years. Br. Med. J. 302:1116-1118.

35. Myers, P., and L.P. Ormerod. 1992. Increased asthma admission rates in Asian patients: Blackburn 1987. Resp. Med. 86:297-300.

36. Leung, R., and P. Ho. 1994. Asthma, allergy, and atopy in three Southeast Asian populations. Thorax. 49:1205-1210.

37. Sherman, C.B., T.D. Tostenson, I.B. Tager, F.E. Speizer, and S. Weiss. 1990. Early childhood predictors of asthma. Am. J. Epidemiol. 132:83-88.

38. Jenkins, M.A., J.L. Hopper, and G.G. Giles. 1993. A population based family study of asthma. Proceedings of Thirteenth Scientific Meeting of International Epidemiological Association. 63 pp.

39. Miletich, J.P., S.M. Prescott, R. White, P.W. Majerus, and E.G. Bovill. 1993. Inherited predisposition to thrombosis. Cell. 72:477-480.

40. Miletich, J.P., I. Sherman, and G. Broze. 1987. Absença of thrombosis in subjects with heterozygous protein C Deficiency. N. Engl. J. Med. 317:991-996.

41. Hutchison, D.C.C. 1988. Natural history of alpha-1-protease inhibitor deficiency. Am. J. Med. 84: 3-12.

42. Guay-Woodford, L.M., G. Muecher, S.D. Hopkins, E.D. Avner, G.G. Germino, A.P. Guillot, J. Herrin, R. Holleman, D.A. Irons, W. Primack, P.D. Thomson, F. B. Waldo, P.W. Lunt, and K. Zerres. 1995. The severe perinatal form of autosomal recessive polycystic kidney disease maps to chromosome 6p21.1-p12: Implications for genetic counseling. Am. J. Hum. Genet. 56:11011107.

43. Liu, A.W., A.V. Delgado-Ezcueta, J.M. Sarratoda, M.E. Alonso, M.T. Medina, M.N. Gee, S. Cordova, H.Z. Zhao, J.M. Spellman, J.R. Ramos Peek, F. Rubio Donnadieu, and R.S. Sparkes. 1995. Juvenile myoclonic epilepsy locus in chromosome 6p21.2-p11: linkage to convulsions and electroencephalography trait. Am. J. Hum. Genet. 57:368-381. 666. .

45. Kato, K., G.D. Clark, N.G. Bazan, and C.F. Zorumski. 1994. Platelet-activating factor as a potential retrograde messenger in CA1 hippocampal longterm potentiation. Nature (Lond.). 367:175-179.

46. Bazan, N.G. 1995. A signal terminator. Nature (Lond.). 374:501-502. 